in vivo $35: 1379-1391(2021)$

doi:10.21873/invivo.12390

Review

\title{
A Ten-year-long Update on Radiation Proctitis Among Prostate Cancer Patients Treated With Curative External Beam Radiotherapy
}

\author{
GIANLUCA FERINI $^{1}$ and STEFANO PERGOLIZZI ${ }^{2}$ \\ ${ }^{1}$ REM Radioterapia, Catania, Italy; \\ ${ }^{2}$ Department of Biomedical and Dental Sciences, \\ Morphological and Functional Images, University of Messina, Messina, Italy
}

\begin{abstract}
This comprehensive synopsis summarizes the most relevant information obtained from a systematic analysis of studies of the last decade on radiation proctitis, one of the most feared radioinduced side effects among prostate cancer patients treated with curative external beam radiotherapy. The present review provides a useful support to radiation oncologists for limiting the onset or improving the treatment of radiation proctitis. This work shows that the past decade was a harbinger of significant new evidence in technological advances and technical tricks to avoid radiation proctitis, in addition to dosimetric perspectives and goals, understanding of pathogenesis, diagnostic work-up and treatment. We believe that a well-rounded knowledge of such an issue is fundamental for its appropriate management.
\end{abstract}

The standard treatments for organ-confined prostate carcinoma are radical prostatectomy or curative radiation therapy with or without anti-androgen drugs. There is no clear advantage in terms of cancer-related overall survival between these two therapeutic approaches; the choice of treatment is discussed among surgeons and radiation oncologists with the patient who chooses how to proceed. Irradiation is an organ-preservation therapy that has some

This article is freely accessible online.

Correspondence to: Gianluca Ferini, MD, REM Radioterapia, Via Penninazzo 11, 95029, Viagrande, Catania, Italy. Tel: +39 3311341117, e-mail: gianlucaferini@hotmail.it

Key Words: Radiation proctitis, External Beam Radiotherapy, prostate cancer, side effects, Intensity modulated radiotherapy, Image guided radiotherapy, dosimetry, supportive care, prevention, cancer care, review. advantages with respect to the surgical approach. In fact, patients submitted to radiotherapy have no anesthesiological risks and a lower incidence of both erectile dysfunction and urinary incontinence. Besides, there is no "strict" age-linked or comorbidity-related contraindication to irradiation.

In the last years, a tremendous amelioration in radiation delivery techniques and planning technologies has made radiation treatments even safer with a lower incidence of radiation-related adverse events. However, to date, there are some concerns with respect to gastrointestinal and genitourinary toxicities, which, in some instances, could determine an interruption of radiotherapy and a lower quality-of-life for patients. Finally, in the most severe cases of anorectal toxicity, aggressive surgical treatment may be necessary to control bleeding or mucosal necrosis.

The aim of this paper is to provide novel key insights into recent technological and pharmacological advances, as well as on possible conceptual reforms, which, within the perspective of a translational medicine, could assist the radiation oncologist in a more careful management of radiation proctitis (RP) among prostate cancer patients treated with curative external beam radiotherapy (EBRT). In particular, we focus our interest on the relevant literature published over the past decade.

\section{Materials and Methods}

We queried the PubMed database with 4 search terms: "radiation", "proctitis", "prostate" and "cancer". We limited the scrutiny of bibliographic entries to articles published from 01/01/2010 to $31 / 12 / 2020$. The most used technique to deliver irradiation is external beam radiation therapy (EBRT) and therefore, we have excluded the works concerning the treatment of prostate cancer with stereotactic radiotherapy (SRT), proton beam (PBT) or carbon ion radiotherapy (CIRT) and with brachytherapy (BT) (or exclusively with its associations, e.g. EBRT $+\mathrm{BT})$, types of radiotherapy (RT) 
of particular complexity and which can lead to a different procedure- or dose-related toxicity profile. Only papers about definitive and adjuvant RT have been selected, excluding those inherent with investigational preoperative settings, as well as reirradiation, curative RT for rare patient subsets (i.e. prostate cancer patients with inflammatory bowel disease). We also disregarded studies on other cancers and/or other radiation induced side effects (i.e. urinary symptoms) or related to special procedures (i.e. rectal spacer injection etc.) and those primarily concerned with cost-effectiveness analysis or territorial surveys. Moreover, we excluded duplicates, case reports and case series with less than 5 patients, articles not available in English or concerning alternative medicine, editorials and commentaries. We also examined all the studies referred to in the retrieved articles, so as not to miss functional articles for the aim of this work. The collection and analysis of bibliographic resources were conducted according to the PRISMA method (Figure 1) and to the following PIO process: Population (prostate cancer patients), Intervention (EBRT, not BT, SRT, PBT or CIRT), Outcome (RP) (Table I).

\section{Results and Discussion}

The search conducted on the basis of the abovementioned time criteria produced 178 results, among which 76 papers were selected according to their relevance for the purposes of this work. Such studies are discussed in detail in the following paragraph, which is further divided into subparagraphs based on the particular topic of the retrieved articles. A few limited bibliographic entries prior to the above time limit have also been included, as they are considered functional to our analysis.

Literature overview. As exemplified by the assessment scales of the leading European and American scientific societies, the most common symptoms experienced by patients with $\mathrm{RP}$ are tenesmus, mucorrhea, pain and bleeding that, from the acute phase, can end in the chronic phase, when fecal incontinence, necrosis and fistula formation could arise (15). Nakamura et al. (6) clearly summarized what factors are associated with proctitis, stating the total radiation dose, fractionation regimens, dose parameters of the critical organs, beam delivery techniques and treatment plan quality as crucial for perception of post-radiation quality of life among prostate cancer patients. Since the clinical review by Garg et al. (7), which indicates the incidence, clinical manifestations, radiation-related and patient risk factors, workup and treatment of proctopathy, new scientific evidence has emerged, more functional and suited to the needs of current clinical practice in radiotherapy.

Technological advances. On the technological side the recent real-world population-based work conducted by Sujenthiran et al. confirms the significant advantage in terms of reduction of gastrointestinal (GI) toxicity among prostate cancer patients treated with intensity-modulated radiotherapy
(IMRT), compared to the 3D-conformal radiotherapy (3DCRT) (8). As a result, IMRT delivered by modern medical linear accelerators (LINACs) removes all sorts of concerns expressed by Roach (9) concerning quality assurance procedures. Bekelman et al. (10) had anticipated Sujenthiran's conclusions, reporting a hazard ratio (HR) for proctitis of 0.78 in favor of intensity-modulated irradiation technique with respect to 3D-CRT in elderly men with nonmetastatic prostate cancer. These results can be further improved by an IMRT guided by a daily online imaging for a more accurate set-up verification and a more precise dose delivery, as demonstrated in a randomized controlled trial conducted by Wortel et al. $(11,12)$. These authors compared image guided IMRT (IG-IMRT) and 3D-CRT for prostate cancer treatment and reported a significant reduction in acute and chronic proctitis rates in favor of the former ([odds ratio $(\mathrm{OR})]=0.54$ and $\mathrm{HR}=0.37$, respectively, $p \leq 0.005$ ), as well as acute genitourinary $(\mathrm{GU})$ toxicity $(\mathrm{OR}=0.59)$, but did not confirm this for chronic GU toxicity $(H R=1.19)$. The value of a correct set-up verification through dedicated imaging would even seem to outweigh the characteristic dose conformity of IMRT. In fact, Hama et al. (13) found excellent disease control outcomes and toxiciy rates with a rough adaptive radiotherapy technique without the use of a multileaf collimator: their method consisted of a first phase during which the prostatic planning target volume (PTV) was irradiated with 2 Anteroposterior/Posteroanterior fields up to a dose of $46 \mathrm{~Gy}$ in $2 \mathrm{~Gy} /$ fractions, followed by a second phase up to a dose of 76 Gy with 2 opposed lateral fields with edges adapted in real-time on daily cone beam computed tomographies (CBCT) and shaped through lead block positioning on the anterior wall of the rectum in order to maximize its sparing. These authors reported a 5-year incidence of grade 2 gastrointestinal adverse events of only $3.8 \%$, compared with a lasting local relapse-free survival rate of almost $100 \%$. Even though the same RT techniques were used [3D-CRT and volumetric modulated arc therapy (VMAT)] for immediate post-operative or salvage purposes, Vogel et al. (14) and Borghetti et al. (15) reported directly opposite results in terms of rectal toxicity: the former reported a higher risk of proctitis for immediate postoperative RT while the second did not show a better tolerance for salvage RT, but only for VMAT, with respect to $3 \mathrm{D}-\mathrm{CRT}(6.3 \%$ vs. $28.4 \%, p=0.006)$, as seen in the immediate postoperative RT group of Vogel's clinical study $(p=0.02)$. The reason for such apparently divergent results may lie in the fact that patients treated with VMAT by Borghetti et al. could rely on image guided set-up verification, unlike those treated by Vogel and colleagues. The reliability of modern IG-IMRT techniques allows for a safe delivery of hypofractionated doses that in a work by Vassis et al. (16) proved to be even less toxic than conventional fractionation. In this case, it should be 


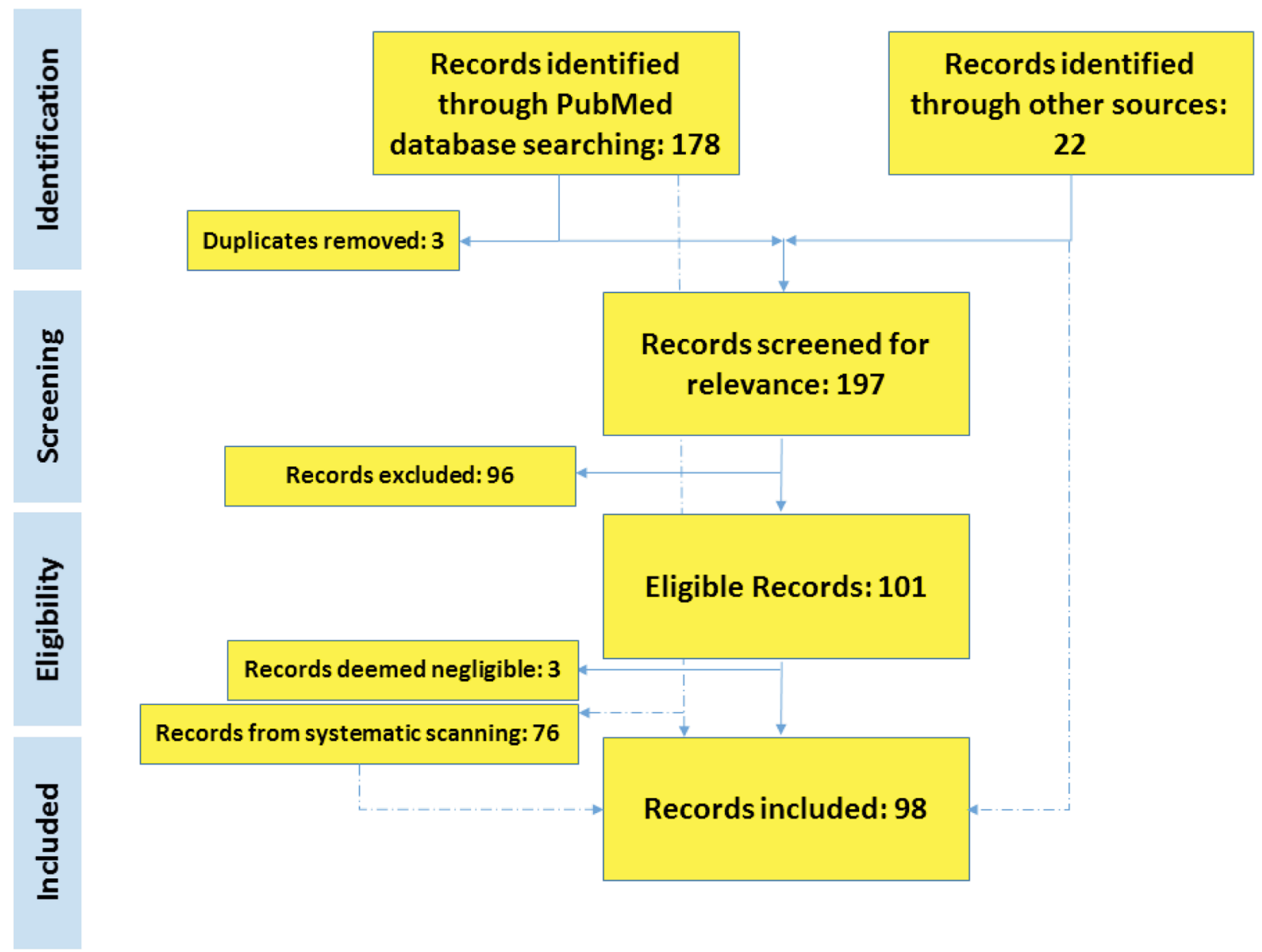

Figure 1. Preferred reporting items for systematic reviews and meta-Analyses (PRISMA) flowchart.

emphasized that hypofractionation also constitutes a financial health benefit, since shortening the total treatment time allows for a reduction in health care costs and the extension of oncologic treatments to a wider population. However, these results do not agree with those previously analysed and discussed in the clinical review and large meta-analysis by Datta et al. (17), as these authors assign a greater risk of acute GI toxicities to hypofractionation than conventional fractionation (risk ratio $=1.470$ ). Although the size of the investigated population in the meta-analysis by Datta et al. $(n=8,146)$ far exceeds that of the sample enrolled in the work of Vassis $(n=110)$, it is extremely heterogeneous, as it includes patients irradiated with 2D-, 3D-CR-, IM- and IGIM-RT, while not providing sufficient details on the risk of proctitis for patients treated with IG-IMRT, which is probably the discriminator to which the low rectal toxicity rate can be attributed in the case of Vassis et al. In the work conducted by Mohammed et al. (18), external beam - image
Table I. Extraction fields using population, intervention and outcome criteria.

\begin{tabular}{lc}
\hline Category & Extraction fields \\
\hline Population & Prostate cancer patients \\
Intervention & EBRT, not BT, SRT, PBT or CIRT \\
Outcome & Radiation Proctitis \\
\hline
\end{tabular}

guided radiotherapy (EB-IGRT) was found to be worse, in terms of acute and chronic GI toxicity, than the other two compared techniques [brachytherapy (BT) alone and EBRT $+\mathrm{BT}]$. In this case, the increased frequency of tenesmus and diarrhea during the acute and chronic rectal bleeding phases could be heavily influenced by two factors: 1) the average larger prostate size of patients treated with exclusive EBIGRT could have resulted in a higher dose to the rectum and 
2) $60 \%$ of the above patients had been treated with 3D-CRT. This latter technique has a lower dose conformity than the IMRT counterpart (40\%); such a difference could turn in a higher damage of the rectum. Gill et al. (19) examined the different patterns of radio-induced toxicity between prostate cancer patients irradiated with and without IGRT, reporting a lower rate of proctitis and haemorrhoid symptoms of borderline significance $(p=0.06)$ in favor of IGRT. Statistical significance was subsequently achieved for prostate cancer patients verified with cone beam $\mathrm{Kv} \mathrm{CT}(\mathrm{CBKvCT})$ versus those verified with electronic portal devices (EPIDs) in the work of Conde-Moreno et al. (20). The irreplaceability of a live IGRT lies in the demonstrated inadequacy of an off-line adaptive process used to define a PTV depending on variation in prostate position: indeed, Parzen et al. found a significantly higher rate of rectal toxicity among patients treated with an Image-Guided Adaptive Radiation Therapy, compared to those treated with BT (21). The ultimate achievement of the IGRT potential derives from works such as those of D'Agostino et al. (22), who published acceptable rectal toxicity rates $(<20 \%)$ in patients with prostate cancer treated with ultrahyprofractionated VMAT and Real-time Electromagnetic Tracking.

Technical ploys. The rectum, albeit a fixed organ in the pelvic cavity, is subject to significant volume changes depending on its gas and stool content that can compromise its exclusion from the radiation field. Various technical solutions have been proposed in order to mechanically limit radiation exposure to the anterior rectal wall, including the application of a hydrogel spacer via transperineal injection in the interspace between the prostate and rectum. This is characterized by an extremely low procedural hazard $(<2 \%)(23)$ and is particularly beneficial in allowing a reduction of rectal volume inside the 70 Gy isodose from $6 \%$ to $2 \%$ (24). This medical intervention has been shown to be effective in significantly reducing chronic RP (25). Mahdavi et al. (26) achieved the same result using a rectal retractor (RR), whose application reduced the dose and dose - volume parameters to the rectal wall, especially for its anterior portion. Such a ploy implied an average reduction of $44.0 \%$ in Grade 2 rectal bleeding in the normal tissue complication probability (NTCP) analysis, when compared with and without RR plans. Among other things, the in vivo measured dosimetry that is performed simultaneously to the treatment delivery, proved to be sufficiently coherent with the planned dose $(67 \%)$, although not reaching the very low discrepancy ( $82 \%$ ) highlighted by Wootton et al. (27), who used another immobilization device, the endorectal balloon. The aforementioned medical device, in addition to ensuring the prostate immobilization for a more accurate radiotherapy, allows a remarkable anterior rectal wall sparing by its dosimetric effect derived from the presence of an air-tissue interface, without compromising the dose coverage for the prostate, as shown by Teh et al. (28). Rastogi et al. (29) demonstrated that online translational corrections guided by daily $\mathrm{kV}-\mathrm{CBCT}$ carried a significantly lower risk of grade $\geq 2$ proctitis if, after merging with CT simulation images, anatomical matching was conducted by fiducial gold markers rather than by bony landmarks (38\% vs. 5.8\%, OR=10.1), emphasizing the usefulness of prostate fiducial marker placement, especially for current clinical practice of dose escalation. All these findings support a dose delivery to the prostate $\geq 74$ Gy for a theoretical better local control. However, the usefulness of such a prescription is questioned by the works of Meng and Lee et al. $(30,31)$ that did not show a therapeutic gain with escalated doses, intended as prolongation of overall and biochemical recurrence free survival, but only a higher rate of moderate-severe rectal toxicity. Clinical Target Volume (CTV) delineation on Magnetic Resonance (MR) images did not reduce the risk of proctitis, but only urinary disorders according to Sander et al. (32). Lafond et al. (33) have shown that optimization of the treatment plan by means of segmentation of the rectum into subvolumes to which stricter dose-volume constraints are applied, decreases the mean dose up to $7.7 \mathrm{~Gy}$ in the risk area. This corresponds to a reduction rate of rectal bleeding equal to $22 \%$, while preserving an adequate target dose coverage.

Dosimetric issues. The fact that the escalated dose corresponds to a greater risk of grade $\geq 2$ proctitis is confirmed by the MRC RT01 Trial with HR equal to 1.64 , when comparing localized prostate cancer patients treated with 3D-CRT for a dose of 74 Gy with the ones limited to 64 Gy (34). Jensen et al. (35) showed that narrower margins of target volumes carried a lower risk of grade $\geq 2$ proctitis for IMRT than for 3D-CRT plans, according to NTCP predictions. The dose-volume constraints for rectum mostly referred to are those published by Michalski et al. (36): V50<50\%, V60<35\%, V65<25\%, V70 $<20 \%$, and V75 $<15 \%$. Compliance with the above limits corresponds to a risk of Grade $\geq 2$ and Grade $\geq 3$ late rectal toxicity less than $15 \%$ and $10 \%$ respectively, at doses up to 79.2 Gy, in 1.8-2 Gy/day fractions. Furthermore, these authors remark that a percentage reduction, albeit of the same order of magnitude (i.e. 5\% in V75 vs. V50), has a clearly different positive prognostic value if achieved at the higher doses and hypothesized that the substantial reduction in the volumes exposed to intermediate doses obtainable with IMRT vs 3DCRT may be important in determining a lower toxicity. The robustness of the constraints proposed by Michalski is confirmed by the results reported by Fuentes-Raspall et al. (37). Pederson et al. (38) showed that keeping even stricter dose-volume constraints, such as rectal V70 $\leq 10 \%$, V65 $\leq 20 \%$, and $\mathrm{V} 40 \leq 40 \%$, practically eliminates the risk of grade $\geq 2$ late proctitis, measured after 4 years. Subsequently there was a gradual conceptual evolution, as in the work of Buettner et al. (39) who proposed that the dosimetric approach, more 
effectively predictive of risk of rectal toxicity, was the one that went beyond the volumetric concept moving towards the shape and location of the dose distribution, thus suggesting the predilection for Dose Surface Histograms (DSH, computing the dose in voxels corresponding to the surface of rectum) over Dose Volume Histograms (DVH). These authors indeed demonstrated a significant correlation with the lateral extent of doses $\geq 61$ Gy exceeding $55 \%$ of the circumference of the rectum. In addition, DSH correlated with proctitis for doses $\geq 59$ Gy. Hamlett et al. (40) used a similar approach to the matter: they showed a significant correlation for grade 2 late proctitis with DVH and DSH ranges between 25-36 Gy, even stronger than that found for doses of 61-67 Gy. The results about hypofractionated doses published by Arunsingh et al. (41) conceptually agree with Buettner's, having shown that the absolute rectal volume is more effective than relative volume in predicting the risk of rectal toxicity. The recommended absolute dose-volume parameters for predicting grade 2 acute proctitis were VEQD2-60Gy $<9.7 \mathrm{cc}$ and VEQD2-50Gy $<15.9$ cc. Also, Ozkan et al. (42) showed a significant correlation of RP only with total rectal volume but not with relative dose-volume parameters (V50, V60, V65, V70 and V75) or even the rectal volume included in PTV. Similarly, Kotabe et al. (43) suggested that dose-volume constraints referring only to the absolute rectal volume are more reliable. They demonstrated how a rectal D5cc $\geq 60$ Gy is significantly associated with late $\geq$ grade 1 rectal bleeding in IG-IMRT, while the relative rectal volume was not. The results published by Mirjolet et al. (44) were along the same lines: the absolute volume of the rectum between $25 \mathrm{~Gy}$ and $50 \mathrm{~Gy}$ correlates significantly with acute toxicity rate, while their relative counterpart does not. These findings were contradicted by the results published by Paleny et al. (45) that reaffirm the correctness of the dosimetric evaluation for the prediction of proctitis referring to the relative and not to the absolute rectal volumes, except for V50Gyccm, which is the only absolute dose volume parameter statistically associated with acute proctitis. Thor et al. (46) suggest that both absolute and relative dose-volume relationships could affect the risk of proctitis. Indeed, it is important to define the absolute rectal volume that receives equal or more than $35 \mathrm{~Gy}$ and the minimum dose delivered to the $5 \%$ of the rectal volume, emphasizing the need for a reduction of hot spots ( $\geq 65 \mathrm{~Gy}$ ). Also, $\mathrm{Ng}$ et al. (47) dwell on high doses having reported that a V70 >14\% was significantly more frequent among patients affected by late proctitis. A higher prescribed radiation dose among prostate cancer patients surveyed using the Expanded Prostate Cancer Index Composite questionnaire was significantly related to a progressive 10 year-long worsening of stool incontinence and rectal bleeding (48). Martínez-Arribas et al. (49) reported a greater risk of proctitis with a mean rectal dose $>45 \mathrm{~Gy}$. Sanguineti et al. (50) proposed the following relative dosevolume constraints in order to minimize the risk of late rectal bleeding when delineating the rectal wall (thickness of $3 \mathrm{~mm}$ ) and treating prostate target with moderately hypofractionated radiotherapy (62 Gy in 3.1 Gy/day fractions): V32 $\leq 50 \%$, V50 $\leq 25.8 \%$ and $\mathrm{V} 60 \leq 10 \%$. The systematic review by Olsson $e t$ al. (51) included, among other things, two studies that proposed rectal volume thresholds for doses ranging from 23 $(<80 \%)$ to $69 \mathrm{~Gy}(<15 \%)$ in order to limit the risk of proctitis using the DVH method. The dosimetric investigation that aims to verify the correspondence between the planned dose and the delivered dose to the rectum has been developed recently. Shelley et al. (52) were the first to reproduce the Dose Surface Maps (DSM) on daily MegaVoltageCT image guidance scans and to generate an accumulated DSM, representitive of the actual total delivered dose. They reported that accumulated DSMs had stronger correlations with rectal bleeding and proctitis, than planned DSMs, with particular reference to quantitative and qualitative spatial distribution of doses $\geq 50$ Gy. Subsequently Casares-Magaz et al. (53) used a similar approach to confirm the discrepancy between the delivered and the planned dose, especially in the inferior sector of the rectum: the extent of high accumulated dose $(\approx 70 \mathrm{~Gy})$ at this level correlated with late GI toxicities. Interestingly, DVH/DSHbased metrics have been proven to be inadequate in finding relationships with symptomatic outcomes. It could be hypothesized that daily on-board CT-imaging can serve as a basis not only for calculating the accumulated DSM, but also for radiomics analysis with the aim of early extracting predictive features of the development of proctitis, as Mostafaei et al. (54) managed to do from pre-treatment CT scans.

Increased understanding of pathogenesis and predictive signatures supporting possible therapeutic implications. Since the works by Gambacorta, Heemsbergen, Barnett et al. (55-57) who highlighted that late rectal damage was consequential to the persistence of an unhealed acute injury, mainly due to inflammatory mediators, new data have emerged which, in addition to increasing knowledge of the pathogenesis of such a radioinduced adverse event, could lay the groundwork for the development of new drugs capable of limiting its occurrence. Beaton et al. (58), for example, compared blood samples from 10 patients that developed grade 3 proctitis with analogous ones collected by 20 patients that experienced no rectal toxicity: they irradiated the blood samples at 6 Gy and observed greater lymphocyte radiosensitivity among patients with grade 3 proctitis. They were then able to offer a valuable predictive indicator for developing a tailored radiotherapy. GhorbanzadehMoghaddam et al. (59) demonstrated that Vitamin D deficiency predisposes to the development of severe acute radio-induced proctitis, promoting its correction when necessary. The increased expression of vascular endothelial growth factor (VEGF) in response to radiation damage could 
be the basis of clinical symptoms and endoscopic rectal mucosa changes in patients with chronic proctitis: it seems responsible for abnormal sprouting angiogenesis, which endoscopically manifests itself with telangiectases tending to easily bleed (60). Microvascular density was significantly increased in post-irradiated rectal mucosa biopsies and related to an increased expression of VEGF and CD31, similarly to the work of Karamanolis (61). A dysfunction at the baseline of the mucosal microvasculature could be at the root of the greater susceptibility of developing proctitis, as hypothesized in the work of Alashkham et al. (62). The enhanced radiation-induced normal tissue damage, such as proctitis found in diabetics due to a pro-oxidative microenvironment, could be counteracted by MnTE-2-PyP, a manganese porphyrin capable of cytoprotection for fibroblast cells of diabetic prostate cancer patients submitted to radiotherapy, without obstructing radiation mediated cancer cell death, as claimed by Chatterjee et al. (63). Kosmacek et al. (64) suggested that damage to fat reservoirs could favor radio-induced rectal fibrosis. Actually, it could trigger myofibroblast formation at the level of the pelvic organs that are unintentionally irradiated. Indeed, adiponectin protects fibroblasts from radioinduced cell death, but not prostate cancer cells in mouse models. Campostrini et al. (65) found that a substantial biopsy-proven gland and crypts loss in anterior rectal wall following irradiation could be considered strongly predictive of late proctitis. These authors recommended delivering a mean dose $\leq 48-52$ Gy to the anterior rectal wall to minimize the depletion of both rectal mucosal gland and crypts. As expected, Luo et al. (66) reported that a larger Gross Tumor Volume (GTV) in patients with locally advanced prostate cancer carries a significantly higher risk of grade G2-G3 acute proctitis, likely due to a greater area of the anterior rectal wall exposed to the high radiation dose. They recorded a HR of 2,132 by comparing GTV greater or equal than and lower than $141 \mathrm{cc}$ and relied on the effectiveness of neoadjuvant androgen deprivation therapy to reduce the prostate size (67). Pathak et al. (68) assume an individual genetic predisposition to the development of proctitis in patients irradiated for adenocarcinoma of the prostate, involving mainly polymorphisms of genes responsible for DNA repair and mithocondrial function. In a large meta-analysis by Kerns et al. (69) one single nucleotide polymorphism (SNP), rs 17055178 , is indicated as significantly associated with the risk of proctitis among the retrospectively collected European ancestry cohorts; however, it was not confirmed in the prospectively accrued Japanese cohorts. Similarly, the REQUITE project is a trial to validate predictive models and biomarkers of radiotherapy toxicity to reduce side-effects and improve quality of life in cancer survivors (70). In the latter cohort of patients, Massi et al. (71) isolated, by means of a deep learning approach, eight SNP signatures that could identify patients most likely to experience adverse effects after radiotherapy for prostate cancer. The genetic susceptibility to develop RP could also have a cancerspecific prognostic value. Eade et al. reported that acute epithelial toxicity after RT for prostate cancer could be considered predictive of tumor radiosensitivity and control. By comparing patients with and without acute toxicities, they observed a gain in terms of freedom from biochemical failure at 5 and 10 years in favor of the former group (72).

Diagnostic work-up. After a careful physical examination and clinical history, proctoscopy plays a key diagnostic role, as well as a prognostic one, as recently highlighted by some studies. In fact, in the work of Campostrini et al. (73), proctoscopy was proven to have a good positive predictive value $(86.67 \%)$ but low sensitivity $(19.4 \%)$. In particular, a significant agreement between acute endoscopic proctitis (AEP) and acute clinical proctitis (ACP) was observed in $13 / 15$ cases. To be thorough, we remark that, within a sample of 67 acutely symptomatic patients, only 13 had a positive endoscopic finding. Furthermore, the combination of ACP and AEP implies a fivefold risk of late clinical proctitis ( $p=0.001)$, which is much greater than that found in patients with ACP only ( $\mathrm{HR}=2.1$, not significant). The prognostic value of proctoscopy can thus support the physician in putting an option for an early and more effective therapy. Furthermore, proctoscopy is able to detect a regression of mucosal damage even up to 65 months after radiotherapy, quantifiable in an improvement rate of $67 \%$ in the work of Goldner et al. (74). These authors found, at first evaluation, telangiectasias in $75 \%$ of the patients, mainly on the more radio-injuried anterior rectal wall area (distal section), and congested mucosa affecting the whole circumference in $50 \%$ of patients. However, they did not indicate how many of these endoscopic findings were actually symptomatic.

Treatment. The readers of this paper can refer to the review recently published by Grodsky et al. (75), which offers an exhaustive overview on possible therapeutic strategies for different grades of radiation proctopathy. They mention, as effective options, among others: sucralfate, anti-inflammatory medications and/or steroids as first line therapy for patients with mild symptoms, formalin instillation or endoscopic argon plasma coagulation (APC) in cases of significant or refractory bleeding as well as surgical procedures, in severe refractory cases, even though they are burdened by high morbidity and mortality. The results published by Takemoto et al. (76) are derived from daily evidence-based practice and agree with the aforementioned therapeutic recommendations: observation, steroid suppositories/enemas or APC, mostly as salvage therapy. These authors suggest limiting the prolonged use of corticosteroids, having recorded a death from septic shock in their cohort; however, that finding was likely 
unrelated to drugs administration. A low-dose acetylsalicylic acid therapy is yet to be demonstrated as clinically effective in decreasing the severity of radiation-induced mucosal inflammation in the rectum, as already shown in wistar rats by Doi et al. (77). Amifostine can be effective in reducing radioinduced damage among prostate cancer patients treated with radical hypofractionated accelerated radiotherapy, as shown in a clinical trial by Koukourakis et al. (78). Stefanelli et al. (79) tested the effectiveness of hyaluronic acid suppositories compared to placebo; they reported only a significant delay on the onset of proctitis in favor of hyaluronic acid $(p=0.04)$, but not a statistically significant difference in its rate between the two groups $(p=0.08)$. Sucralfate paste enemas have been proven to be successful in leading to a discreet improvement of haemorrhagic RP in a series of 23 patients (80). However, oral administration of sucralfate does not provide an additional clinical benefit when paired with APC sessions for chronic haemorrhagic RP (81). In a clinical trial conducted by Maggio et al. (82), daily sodium butyrate enema showed no efficacy in reducing the incidence, severity and duration of acute RP. This adverse event was significantly related only to preexisting clinical status (e.g. diabetes or hemorrhoids). Alashkham et al. (83) showed that hypertensive prostate cancer patients, taking angiotensin-converting enzyme (ACE) inhibitors during radical radiation therapy combined with hormone therapy, developed significantly lower high grade proctitis compared to non-hypertensive patients or hypertensive patients not taking ACE inhibitors. Jensen et al. (84) managed to convey a semi-synthetic glycosaminoglycan (GAG) to the rectal mucosa through a gel composed of silk-elastinlike protein polymers, specifically designed to enhance topical absorption of GAG. They documented a good effectiveness of this medical device in mouse models. Similarly, a pilot randomized trial about the effectiveness of intra-rectal administration of epinephrine, whose rationale lies in its radio-protective ischemizing effect, has not achieved the expected goal in reducing the rate of RP (85). Sahebnasagh et al. (86) demonstrated that Aloe vera topical ointment could be effective in prevention of RP; this finding is particularly notable given the non-existent toxicity profile of this product. In a randomized controlled phase II trial conducted by Saadipoor et al. (87), oral nanocurcumin was not superior to placebo in preventing or mitigating symptoms of proctitis in patients undergoing RT for prostate cancer, but this fact could be due to the lack of a sufficiently large sample size to identify a statistically significant difference (underpowered study). Nascimento et al. (88) showed, in another randomized controlled trial, the protective ability of symbiotics such as Lactobacillus reuteri, at the level of rectal mucosa. APC seems highly effective in stopping chronic rectal bleeding refractory to medical treatment; in the experience of Swan et al. (89); a single-session was sufficient in $68 \%$ of cases
$(34 / 50)$, while a second session achieved a success rate of $96 \%$. This medical procedure worked well even in all 16 patients in whom previous treatment for chronic RP failed, but $17 / 50$ patients complained about short-term complications ( $<6$ weeks), such as proctalgia (13), rectal mucous discharge (4), incontinence (1), fever (1), and bleeding (1), and only one a long-term complication, i.e. an asymptomatic rectal stricture. Likewise, in the work of Hortelano et al. (90) APC controlled or reduced bleeding in almost all patients (28/30), triggering only a grade 2 rectal ulceration and a grade 2 rectal incontinence, which spontaneously fully recovered after six months and persistently regressed to grade 1 toxicity at 34 months, respectively. These findings should be regarded with cautiousness as Weiner et al. (91) reported post-APC ulceration in 8 cases $(22.9 \%)$ plus 2 life-threatening toxicities $(5.7 \%)$, including rectovesicular fistula, one of which actually resulted in the patient's death, probably due to a very short session interval $(<24 \mathrm{~h})$. APC was also compared to formalin in a randomized controlled trial carried out by Yeoh et al. (92), who showed an excellent effectiveness for both medications in long-lasting control of chronic radio-induced rectal bleeding, but also unresolved anorectal symptoms, or even an asymptomatic worsening of rectal compliance and anorectal sensory function, in most patients. Topical instillation of a solution of $4 \%$ formalin was well-tolerated and effective in stopping rectal bleeding in a mixed cohort of patients (prostate and vaginocervical cancer), having the advantage of repeatability due to its safety profile (93). These results have been confirmed by Viani et al. (94) that showed a global efficacy rate equal to $94 \%$ in 35 prostate cancer patients previously submitted to radiotherapy without any serious side effect and need for blood transfusion. In a study by Clavo et al. (95) with a small sample size (12 prostate cancer and 5 gynecologic cancer patients), ozone therapy was shown to be useful in the management of persistent radioinduced rectal bleeding, but this finding needs further confirmation by larger clinical trials. In addition, hyperbaric oxygen (HBO) is one of the most-documented alternative therapies. In a prospective cohort study by Oscarsson et al. (96) it has been proven to be effective in $89 \%$ of patients with late RP, leading to a significant long-lasting relief of symptoms. Specifically, just after the treatment they recorded a relative improvement equal to $24 \%$, almost confirmed (21\%) at 6 to 12 -month follow-up. Neither seizures nor otic barotrauma due to oxygen toxicity were experienced by any patient. In an observational study by Andren et al. (97) the symptomatologic improvement was in the amount of a reduction of 3.8 in the LENT-SOMA score for late RP comparing pre- and post-treatment conditions $(p=0.004)$ with no significant adverse events. Radiofrequency ablation is an alternative therapeutic option, shown to be an effective treatment by Rustagi et al. (98); permanent stoppage of rectal bleeding was achieved in all patients. If chronic proctitis 
establishes itself in a context of a hemorrhoidal disease, rubber band ligation of such a venous plexus might be necessary and should be associated with one of the above therapies (99). Also diverting colostomy is an effective solution capable of restoring satisfactory hemoglobin levels and significantly improving the quality of life of patients suffering from severe hemorrhagic chronic RP (100). Recently a novel approach using colonic water irrigation and oral antibiotics demonstrated the efficacy of this kind of treatment in a randomized controlled trial (101). Another endoscopic-guided treatment is the application of Purastat, a haemostatic agent, which was demonstrated to be successful in 21 patients with severe RP (102). Lastly, the recent review by Weiner et al. (103) efficaciously summarizes all endoscopic and non-endoscopic approaches for the management of radiation-induced rectal bleeding currently used in daily clinical practice.

\section{Conclusion}

Accurate patient positioning and set-up verification are the best tools to prevent RP (104). Traditional DVH constraint analysis systems seem reliable; however, new approaches to assess the rectal dose are gradually carving out more space in clinical practice, as they are potentially more effective in predicting the risk of proctitis, such as by means of DSM. From this perspective, the rectum emerges as a serial organ at risk (OAR), which it actually is, and for this reason the dose absorbed by its subvolumes, quantified in cubic centimeters and not in percentage, is of particular importance in determining the risk of developing RP. The spacing of the rectum from the radiation field through hoc spacers, as well as other technical tricks, is equally effective in lowering such a risk. In recent years, new evidence has been provided about the pathogenesis and treatment of RP. This is a topic of enormous interest among radiation oncologists and a more mature knowledge of it will allow for a better management of this issue.

\section{References}

1 Cox JD, Stetz J and Pajak TF: Toxicity criteria of the Radiation Therapy Oncology Group (RTOG) and the European Organization for Research and Treatment of Cancer (EORTC). Int J Radiat Oncol Biol Phys 31(5): 1341-1346, 1995. PMID: 7713792. DOI: 10.1016/0360-3016(95)00060-C

2 LENT SOMA scales for all anatomic sites. Int J Radiat Oncol Biol Phys 31(5): 1049-1091, 1995. PMID: 7713776. DOI: 10.1016/0360-3016(95)90159-0

3 Common Terminology Criteria for Adverse Events (CTCAE) Version 5.0. Available at: https://ctep.cancer.gov/protocol development/electronic_applications/docs/ctcae_v5_quick_referenc e_8.5x11.pdf [Last accessed on February 12, 2021]

4 Dueck AC, Mendoza TR, Mitchell SA, Reeve BB, Castro KM, Rogak LJ, Atkinson TM, Bennett AV, Denicoff AM, O’Mara AM, Li Y, Clauser SB, Bryant DM, Bearden JD 3rd, Gillis TA, Harness
JK, Siegel RD, Paul DB, Cleeland CS, Schrag D, Sloan JA, Abernethy AP, Bruner DW, Minasian LM, Basch E and National Cancer Institute PRO-CTCAE Study Group: Validity and reliability of the us national cancer institute's patient-reported outcomes version of the common terminology criteria for adverse events (PRO-CTCAE). JAMA Oncol 1(8): 1051-1059, 2015. PMID: 26270597. DOI: 10.1001/jamaoncol.2015.2639

5 Pergolizzi S, Maranzano E, De Angelis V, Lupattelli M, Frata P, Spagnesi S, Frisio ML, Mandoliti G, Delia P, Malinverni G, Trippa F, Fabbietti L, Parisi S, De Vecchi P, Sansotta G, Giorgetti C, Bergami T, Orecchia R, Portaluri M, Signor M, Pontoriero A, Santacaterina A, Di Gennaro D and Italian Group for Antiemetic Research in Radiotherapy - IGARR: Diarrhoea in irradiated patients: a prospective multicentre observational study. Dig Liver Dis 45(11): 933-937, 2013. PMID: 23790323. DOI: $10.1016 /$ j.dld.2013.04.012

6 Nakamura K, Konishi K, Komatsu T and Ishiba R: Quality of life after external beam radiotherapy for localized prostate cancer: Comparison with other modalities. Int J Urol 26(10): 950-954, 2019. PMID: 31131492. DOI: 10.1111/iju.14026

7 Garg AK, Mai WY, McGary JE, Grant WH 3rd, Butler EB and Teh BS: Radiation proctopathy in the treatment of prostate cancer. Int J Radiat Oncol Biol Phys 66(5): 1294-1305, 2006. PMID: 17126204. DOI: 10.1016/j.ijrobp.2006.07.1386

8 Sujenthiran A, Nossiter J, Charman SC, Parry M, Dasgupta P, van der Meulen J, Cathcart PJ, Clarke NW, Payne H and Aggarwal A: National population-based study comparing treatment-related toxicity in men who received intensity modulated versus 3-dimensional conformal radical radiation therapy for prostate cancer. Int J Radiat Oncol Biol Phys 99(5): 1253-1260, 2017. PMID: 28974414. DOI: 10.1016/j.ijrobp.2017.07.040

9 Roach M 3rd: Reducing the toxicity associated with the use of radiotherapy in men with localized prostate cancer. Urol Clin North Am 31(2): 353-366, 2004. PMID: 15123413. DOI: 10.1016/j.ucl.2004.02.001

10 Bekelman JE, Mitra N, Efstathiou J, Liao K, Sunderland R, Yeboa $\mathrm{DN}$ and Armstrong K: Outcomes after intensity-modulated versus conformal radiotherapy in older men with nonmetastatic prostate cancer. Int J Radiat Oncol Biol Phys 81(4): e325-e334, 2011. PMID: 21498008. DOI: 10.1016/j.ijrobp.2011.02.006

11 Wortel RC, Incrocci L, Pos FJ, Lebesque JV, Witte MG, van der Heide UA, van Herk M and Heemsbergen WD: Acute toxicity after image-guided intensity modulated radiation therapy compared to 3D conformal radiation therapy in prostate cancer patients. Int J Radiat Oncol Biol Phys 91(4): 737-744, 2015. PMID: 25752386. DOI: 10.1016/j.ijrobp.2014.12.017

12 Wortel RC, Incrocci L, Pos FJ, van der Heide UA, Lebesque JV, Aluwini S, Witte MG and Heemsbergen WD: Late side effects after image guided intensity modulated radiation therapy compared to 3D-conformal radiation therapy for prostate cancer: Results from 2 prospective cohorts. Int J Radiat Oncol Biol Phys 95(2): 680-689, 2016. PMID: 27055398. DOI: 10.1016/j.ijrobp. 2016.01 .031

13 Hama Y and Kaji T: Long-term follow-up results of CT-guided daily adaptive radiation therapy for localized prostate cancer. Anticancer Res 38(10): 5959-5962, 2018. PMID: 30275225. DOI: $10.21873 /$ anticanres.12942

14 Vogel MME, Kessel KA, Gschwend JE, Weichert W, Wilkens JJ and Combs SE: Early and late toxicity profiles of patients 
receiving immediate postoperative radiotherapy versus salvage radiotherapy for prostate cancer after prostatectomy. Strahlenther Onkol 195(2): 131-144, 2019. PMID: 30182246. DOI: $10.1007 / \mathrm{s} 00066-018-1359-2$

15 Borghetti P, Spiazzi L, Cozzaglio C, Pedretti S, Caraffini B, Triggiani L, Greco D, Bardoscia L, Barbera F, Buglione M and Magrini SM: Postoperative radiotherapy for prostate cancer: the sooner the better and potential to reduce toxicity even further. Radiol Med 123(1): 63-70, 2018. PMID: 28924967. DOI: 10.1007/s11547-017-0807-x

16 Vassis S, Nöldeke B, Christiansen H, von Klot CA and Merten R: Moderately HRT vs. CRT for localized prostate cancer using image-guided VMAT with SIB: evaluation of acute and late toxicities. Strahlenther Onkol 196(7): 598-607, 2020. PMID: 32040691. DOI: 10.1007/s00066-020-01589-w

17 Datta NR, Stutz E, Rogers S and Bodis S: Conventional versus hypofractionated radiation therapy for localized or locally advanced prostate cancer: A systematic review and metaanalysis along with therapeutic implications. Int J Radiat Oncol Biol Phys 99(3): 573-589, 2017. PMID: 29280452. DOI: 10.1016/j.ijrobp.2017.07.021

18 Mohammed N, Kestin L, Ghilezan M, Krauss D, Vicini F, Brabbins D, Gustafson G, Ye H and Martinez A: Comparison of acute and late toxicities for three modern high-dose radiation treatment techniques for localized prostate cancer. Int J Radiat Oncol Biol Phys 82(1): 204-212, 2012. PMID: 21167653. DOI: 10.1016/j.ijrobp.2010.10.009

19 Gill S, Thomas J, Fox C, Kron T, Rolfo A, Leahy M, Chander S, Williams S, Tai KH, Duchesne GM and Foroudi F: Acute toxicity in prostate cancer patients treated with and without image-guided radiotherapy. Radiat Oncol 6: 145, 2011. PMID: 22035354. DOI: 10.1186/1748-717X-6-145

20 Conde-Moreno AJ, Ferrer-Albiach C, Zabaleta-Meri M, JuanSenabre XJ and Santos-Serra A: The contribution of the cone beam Kv CT (CBKvCT) to the reduction in toxicity of prostate cancer treatment with external 3D radiotherapy. Clin Transl Oncol 14(11): 853-863, 2012. PMID: 23054750. DOI: 10.1007/s 12094-012-0871-6

21 Parzen JS, Ye H, Gustafson G, Yan D, Martinez A, Chen PY, Ghilezan M, Sebastian E, Limbacher A and Krauss DJ: Rates of rectal toxicity in patients treated with high dose rate brachytherapy as monotherapy compared to dose-escalated external beam radiation therapy for localized prostate cancer. Radiother Oncol 147: 123-129, 2020. PMID: 32276193. DOI: 10.1016/j.radonc 2020.03 .033

22 D’Agostino GR, Mancosu P, Di Brina L, Franzese C, Pasini L, Iftode C, Comito T, De Rose F, Guazzoni GF and Scorsetti M: Stereotactic body radiation therapy for intermediate-risk prostate cancer with VMAT and real-time electromagnetic tracking: A Phase II Study. Am J Clin Oncol 43(9): 628-635, 2020. PMID: 32889832. DOI: 10.1097/COC.00000000 00000721

23 Müller AC, Mischinger J, Klotz T, Gagel B, Habl G, Hatiboglu $\mathrm{G}$ and Pinkawa $\mathrm{M}$ : Interdisciplinary consensus statement on indication and application of a hydrogel spacer for prostate radiotherapy based on experience in more than 250 patients. Radiol Oncol 50(3): 329-36, 2016. PMID: 27679550. DOI: 10.1515/raon-2016-0036

24 Pinkawa M, Klotz J, Djukic V, Schubert C, Escobar-Corral N, Caffaro M, Piroth MD, Holy R and Eble MJ: Learning curve in the application of a hydrogel spacer to protect the rectal wall during radiotherapy of localized prostate cancer. Urology 82(4): 963-968, 2013. PMID: 24074991. DOI: 10.1016/j.urology.2013.07.014

25 Te Velde BL, Westhuyzen J, Awad N, Wood M and Shakespeare TP: Late toxicities of prostate cancer radiotherapy with and without hydrogel SpaceAOR insertion. J Med Imaging Radiat Oncol 63(6): 836-841, 2019. PMID: 31520465. DOI: 10.1111/ 1754-9485.12945

26 Mahdavi SR, Ghaffari H, Mofid B, Rostami A, Reiazi R and Janani L: Rectal retractor application during image-guided dose-escalated prostate radiotherapy. Strahlenther Onkol 195(10): 923-933, 2019. PMID: 30824942. DOI: 10.1007/ s00066-019-01445-6

27 Wootton L, Kudchadker R, Lee A and Beddar S: Real-time in vivo rectal wall dosimetry using plastic scintillation detectors for patients with prostate cancer. Phys Med Biol 59(3): 647-660, 2014. PMID: 24434775. DOI: 10.1088/0031-9155/59/3/647

28 Teh BS, Dong L, McGary JE, Mai WY, Grant W 3rd and Butler EB: Rectal wall sparing by dosimetric effect of rectal balloon used during intensity-modulated radiation therapy (IMRT) for prostate cancer. Med Dosim 30(1): 25-30, 2005. PMID: 15749008. DOI: $10.1016 /$ j.meddos.2004.10.005

29 Rastogi M, Nanda SS, Gandhi AK, Dalela D, Khurana R, Mishra SP, Srivastava A, Farzana S, Bhatt MLB and Husain N: Pelvic bone anatomy vs implanted gold seed marker registration for image-guided intensity modulated radiotherapy for prostate carcinoma: Comparative analysis of inter-fraction motion and toxicities. J Egypt Natl Canc Inst 29(4): 185-190, 2017. PMID: 29129577. DOI: 10.1016/j.jnci.2017.08.003

30 Meng K, Lim K, Lee CC, Chia D, Ooi KH, Soon YY and Tey $\mathrm{J}$ : Clinical outcomes of dose-escalated radiotherapy for localised prostate cancer: A single-institution experience. In Vivo 34(2): 757-765, 2020. PMID: 32111781. DOI: 10.21873/invivo. 11835

31 Lee CC, Lim KH, Chia DW, Chong YL, Png KS, Chong KT, Soon YY and Tey JC: Clinical outcomes of external beam radiotherapy in patients with localized prostate cancer: Does dose escalation matter? Asia Pac J Clin Oncol 15(6): 323-330, 2019. PMID: 31332959 . DOI: 10.1111/ajco.13197

32 Sander L, Langkilde NC, Holmberg M and Carl J: MRI target delineation may reduce long-term toxicity after prostate radiotherapy. Acta Oncol 53(6): 809-814, 2014. PMID: 24358954. DOI: 10.3109/0284186X.2013.865077

33 Lafond C, Barateau A, N'Guessan J, Perichon N, Delaby N, Simon A, Haigron P, Mylona E, Acosta O and de Crevoisier R: Planning with patient-specific rectal sub-region constraints decreases probability of toxicity in prostate cancer radiotherapy. Front Oncol 10: 1597, 2020. PMID: 33042802. DOI: 10.3389/fonc. 2020.01597

34 Syndikus I, Morgan RC, Sydes MR, Graham JD, Dearnaley DP and MRC RT01 collaborators.: Late gastrointestinal toxicity after dose-escalated conformal radiotherapy for early prostate cancer: results from the UK Medical Research Council RT01 trial (ISRCTN47772397). Int J Radiat Oncol Biol Phys 77(3): 773-783, 2010. PMID: 19836155. DOI: 10.1016/j.ijrobp.2009. 05.052

35 Jensen I, Carl J, Lund B, Larsen EH and Nielsen J: Radiobiological impact of reduced margins and treatment technique for prostate cancer in terms of tumor control probability (TCP) and normal tissue complication probability 
(NTCP). Med Dosim 36(2): 130-137, 2011. PMID: 20488692 DOI: 10.1016/j.meddos.2010.02.004

36 Michalski JM, Gay H, Jackson A, Tucker SL and Deasy JO: Radiation dose-volume effects in radiation-induced rectal injury. Int J Radiat Oncol Biol Phys 76(3 Suppl): S123-129, 2010. PMID: 20171506. DOI: 10.1016/j.ijrobp.2009.03.078

37 Fuentes-Raspall R, Inoriza JM, Rosello-Serrano A, Auñón-Sanz C, Garcia-Martin P and Oliu-Isern G: Late rectal and bladder toxicity following radiation therapy for prostate cancer: Predictive factors and treatment results. Rep Pract Oncol Radiother 18(5): 298-303, 2013. PMID: 24416567. DOI: 10.1016/j.rpor.2013.05.006

38 Pederson AW, Fricano J, Correa D, Pelizzari CA and Liauw SL: Late toxicity after intensity-modulated radiation therapy for localized prostate cancer: an exploration of dose-volume histogram parameters to limit genitourinary and gastrointestinal toxicity. Int J Radiat Oncol Biol Phys 82(1): 235-241, 2012. PMID: 21163587. DOI: 10.1016/j.ijrobp.2010.09.058

39 Buettner F, Gulliford SL, Webb S, Sydes MR, Dearnaley DP and Partridge M: Assessing correlations between the spatial distribution of the dose to the rectal wall and late rectal toxicity after prostate radiotherapy: an analysis of data from the MRC RT01 trial (ISRCTN 47772397). Phys Med Biol 54(21): 65356548, 2009. PMID: 19826203. DOI: 10.1088/0031-9155/54/ $21 / 006$

40 Hamlett LJ, McPartlin AJ, Maile EJ, Webster G, Swindell R, Rowbottom CG, Choudhury A and Aitkenhead AH: Parametrized rectal dose and associations with late toxicity in prostate cancer radiotherapy. Br J Radiol 88(1054): 20150110, 2015. PMID: 26246172. DOI: 10.1259/bjr.20150110

41 Arunsingh M, Mallick I, Prasath S, Arun B, Sarkar S, Shrimali RK, Chatterjee S and Achari R: Acute toxicity and its dosimetric correlates for high-risk prostate cancer treated with moderately hypofractionated radiotherapy. Med Dosim 42(1): 18-23, 2017. PMID: 28129973. DOI: 10.1016/j.meddos. 2016.10.002

42 Ozkan EE, Ozseven A and Cerkesli ZAK: Evaluating the predictive value of quantec rectum tolerance dose suggestions on acute rectal toxicity in prostate carcinoma patients treated with IMRT. Rep Pract Oncol Radiother 25(1): 50-54, 2020. PMID: 31889921. DOI: 10.1016/j.rpor.2019.12.002

43 Kotabe K, Nakayama H, Takashi A, Takahashi A, Tajima T and Kume H: Association between rectal bleeding and the absolute dose volume of the rectum following image-guided radiotherapy for patients with prostate cancer. Oncol Lett 16(2): 2741-2749, 2018. PMID: 30013669. DOI: 10.3892/ol.2018.8888

44 Mirjolet C, Walker PM, Gauthier M, Dalban C, Naudy S, Mazoyer F, Martin E, Maingon P and Créhange G: Absolute volume of the rectum and AUC from rectal DVH between $25 \mathrm{~Gy}$ and $50 \mathrm{~Gy}$ predict acute gastrointestinal toxicity with IGIMRT in prostate cancer. Radiat Oncol 11(1): 145, 2016. PMID: 27814726. DOI: 10.1186/s13014-016-0721-8

45 Paleny R, Bremer M, Walacides D, Mainwaring S, Weber K and Henkenberens C: Comparison of relative and absolute rectal dose-volume parameters and clinical correlation with acute and late radiation proctitis in prostate cancer patients. Strahlenther Onkol 195(2): 103-112, 2019. PMID: 30191285. DOI: $10.1007 / \mathrm{s} 00066-018-1365-4$

46 Thor M, Deasy JO, Paulus R, Robert Lee W, Amin MB, Bruner DW, Low DA, Shah AB, Malone SC, Michalski JM, Dayes IS,
Seaward SA, Gore EM, Albert M, Pisansky TM, Faria SL, Chen Y, Koontz BF, Swanson GP, Pugh SL and Sandler HM: Tolerance doses for late adverse events after hypofractionated radiotherapy for prostate cancer on trial NRG Oncology/RTOG 0415. Radiother Oncol 135: 19-24, 2019. PMID: 31015166. DOI: 10.1016/j.radonc.2019.02.014

$47 \mathrm{Ng}$ BYH, Yu ELM, Lau TTS, Law KS and Cheng ACK: Associations of clinical and dosimetric parameters with late rectal toxicities after radical intensity-modulated radiation therapy for prostate cancer: a single-centre retrospective study. Hong Kong Med J 25(6): 460-467, 2019. PMID: 31796645. DOI: $10.12809 / \mathrm{hkmj} 198037$

48 Pinkawa M, Gharib A, Schlenter M, Timm L and Eble MJ: Quality of life more than 10 years after radiotherapy for localized prostate cancer-impact of time after treatment and prescription dose. Qual Life Res, 2020. PMID: 33034812. DOI: 10.1007/s11136-020-02639-7

49 Martínez-Arribas CM, González-San Segundo C, CuestaÁlvaro P and Calvo-Manuel FA: Predictors of urinary and rectal toxicity after external conformed radiation therapy in prostate cancer: Correlation between clinical, tumour and dosimetric parameters and radical and postoperative radiation therapy. Actas Urol Esp 41(10): 615-623, 2017. PMID: 28625534. DOI: 10.1016/j.acuro.2017.03.010

50 Sanguineti G, Faiella A, Farneti A, D’Urso P, Fuga V, Olivieri M, Giannarelli D, Marzi S, Iaccarino G and Landoni V: Refinement \& validation of rectal wall dose volume objectives for prostate hypofractionation in 20 fractions. Clin Trans1 Radiat Oncol 21: 91-97, 2020. PMID: 32072030. DOI: 10.1016/j.ctro.2020.01.006

51 Olsson CE, Jackson A, Deasy JO and Thor M: A Systematic Post-QUANTEC Review of Tolerance Doses for Late Toxicity After Prostate Cancer Radiation Therapy. Int J Radiat Oncol Biol Phys 102(5): 1514-1532, 2018. PMID: 30125635. DOI: 10.1016/j.ijrobp.2018.08.015

52 Shelley LEA, Scaife JE, Romanchikova M, Harrison K, Forman JR, Bates AM, Noble DJ, Jena R, Parker MA, Sutcliffe MPF, Thomas SJ and Burnet NG: Delivered dose can be a better predictor of rectal toxicity than planned dose in prostate radiotherapy. Radiother Oncol 123(3): 466-471, 2017. PMID: 28460825. DOI: $10.1016 /$ j.radonc.2017.04.008

53 Casares-Magaz O, Bülow S, Pettersson NJ, Moiseenko V, Pedersen J, Thor M, Einck J, Hopper A, Knopp R and Muren LP: High accumulated doses to the inferior rectum are associated with late gastro-intestinal toxicity in a case-control study of prostate cancer patients treated with radiotherapy. Acta Oncol 58(10): 1543-1546, 2019. PMID: 31364905. DOI: 10.1080/0284186X.2019.1632476

54 Mostafaei S, Abdollahi H, Kazempour Dehkordi S, Shiri I, Razzaghdoust A, Zoljalali Moghaddam SH, Saadipoor A, Koosha F, Cheraghi S and Mahdavi SR: CT imaging markers to improve radiation toxicity prediction in prostate cancer radiotherapy by stacking regression algorithm. Radiol Med 125(1): 87-97, 2020. PMID: 31552555. DOI: 10.1007/s11547019-01082-0

55 Gambacorta MA, Manfrida S, D’Agostino G, Digesù C, D'Onofrio I, Rosato H and Valentini V: Impact of dose and volume on rectal tolerance. Rays 30(2): 181-7, 2005. PMID: 16294912.

56 Heemsbergen WD, Peeters ST, Koper PC, Hoogeman MS and Lebesque JV: Acute and late gastrointestinal toxicity after 
radiotherapy in prostate cancer patients: consequential late damage. Int J Radiat Oncol Biol Phys 66(1): 3-10, 2006. PMID: 16814954. DOI: 10.1016/j.ijrobp.2006.03.055

57 Barnett GC, De Meerleer G, Gulliford SL, Sydes MR, Elliott RM and Dearnaley DP: The impact of clinical factors on the development of late radiation toxicity: results from the Medical Research Council RT01 trial (ISRCTN47772397). Clin Oncol (R Coll Radiol) 23(9): 613-624, 2011. PMID: 21470834. DOI: 10.1016/j.clon.2011.03.001

58 Beaton LA, Ferrarotto C, Marro L, Samiee S, Malone S, Grimes S, Malone K and Wilkins RC: Chromosome damage and cell proliferation rates in in vitro irradiated whole blood as markers of late radiation toxicity after radiation therapy to the prostate. Int J Radiat Oncol Biol Phys 85(5): 1346-1352, 2013. PMID: 23158059. DOI: 10.1016/j.ijrobp.2012.09.026

59 Ghorbanzadeh-Moghaddam A, Gholamrezaei A and Hemati S: Vitamin d deficiency is associated with the severity of radiationinduced proctitis in cancer patients. Int J Radiat Oncol Biol Phys 92(3): 613-618, 2015. PMID: 25890844. DOI: 10.1016/j.ijrobp. 2015.02.011

60 Trzcinski R, Dziki A, Brys M, Moszynska-Zielinska M, Chalubinska-Fendler J, Mik M, Kujawski R and Dziki L: Expression of vascular endothelial growth factor and its correlation with clinical symptoms and endoscopic findings in patients with chronic radiation proctitis. Colorectal Dis 20(4): 321-330, 2018. PMID: 28963746. DOI: 10.1111/codi.13902

61 Karamanolis G, Delladetsima I, Kouloulias V, Papaxoinis K, Panayiotides I, Haldeopoulos D, Triantafyllou K, Kelekis N and Ladas SD: Increased expression of VEGF and CD31 in postradiation rectal tissue: implications for radiation proctitis. Mediators Inflamm 2013: 515048, 2013. PMID: 23737650. DOI: $10.1155 / 2013 / 515048$

62 Alashkham A, Paterson C, Hubbard S and Nabi G: What is the impact of diabetes mellitus on radiation induced acute proctitis after radical radiotherapy for adenocarcinoma prostate? A prospective longitudinal study. Clin Transl Radiat Oncol 14: 5963, 2017. PMID: 30623118. DOI: 10.1016/j.ctro.2017.02.003

63 Chatterjee A, Kosmacek EA, Shrishrimal S, McDonald JT and Oberley-Deegan RE: MnTE-2-PyP, a manganese porphyrin, reduces cytotoxicity caused by irradiation in a diabetic environment through the induction of endogenous antioxidant defenses. Redox Biol 34: 101542, 2020. PMID: 32361681. DOI: $10.1016 /$ j.redox.2020.101542

64 Kosmacek EA and Oberley-Deegan RE: Adipocytes protect fibroblasts from radiation-induced damage by adiponectin secretion. Sci Rep 10(1): 12616, 2020. PMID: 32724116. DOI: 10.1038/s41598-020-69352-w

65 Campostrini F, Remo A, Astati L, Zorzi M, Capodaglio G, Buffoli A, Moretti G, Della Monica B, Zanella C and Verlato $\mathrm{G}$ : Association between acute histopathological changes of rectal walls and late radiation proctitis following radiotherapy for prostate cancer. Strahlenther Onkol 196(7): 617-627, 2020. PMID: 32166451. DOI: 10.1007/s00066-020-01590-3

66 Luo HC, Cheng HH, Lin GS, Fu ZC and Li DS: Intensitymodulated radiotherapy combined with endocrine therapy for intermediate and advanced prostate cancer: long-term outcome of Chinese patients. Asian Pac J Cancer Prev 14(8): 4711-4715, 2013. PMID: 24083731. DOI: 10.7314/apjcp.2013.14.8.4711

67 Peeters ST, Hoogeman MS, Heemsbergen WD, Slot A, Tabak H, Koper PC and Lebesque JV: Volume and hormonal effects for acute side effects of rectum and bladder during conformal radiotherapy for prostate cancer. Int J Radiat Oncol Biol Phys 63(4): 1142-1152, 2005. PMID: 15939547. DOI: 10.1016/j.ijrobp.2005.03.060

68 Pathak GA, Polimanti R, Silzer TK, Wendt FR, Chakraborty R and Phillips NR: Genetically-regulated transcriptomics \& copy number variation of proctitis points to altered mitochondrial and DNA repair mechanisms in individuals of European ancestry. BMC Cancer 20(1): 954, 2020. PMID: 33008348. DOI: 10.1186/s 12885-020-07457-1

69 Kerns SL, Fachal L, Dorling L, Barnett GC, Baran A, Peterson DR, Hollenberg M, Hao K, Narzo AD, Ahsen ME, Pandey G, Bentzen SM, Janelsins M, Elliott RM, Pharoah PDP, Burnet NG, Dearnaley DP, Gulliford SL, Hall E, Sydes MR, AguadoBarrera ME, Gómez-Caamaño A, Carballo AM, Peleteiro P, Lobato-Busto R, Stock R, Stone NN, Ostrer H, Usmani N, Singhal S, Tsuji H, Imai T, Saito S, Eeles R, DeRuyck K, Parliament M, Dunning AM, Vega A, Rosenstein BS and West CML: Radiogenomics consortium genome-wide association study meta-analysis of late toxicity after prostate cancer radiotherapy. J Natl Cancer Inst 112(2): 179-190, 2020. PMID: 31095341. DOI: 10.1093/jnci/djz075

70 Seibold P, Webb A, Aguado-Barrera ME, Azria D, Bourgier C, Brengues M, Briers E, Bultijnck R, Calvo-Crespo P, Carballo A, Choudhury A, Cicchetti A, Claßen J, Delmastro E, Dunning AM, Elliott RM, Fachal L, Farcy-Jacquet MP, Gabriele P, Garibaldi E, Gómez-Caamaño A, Gutiérrez-Enríquez S, Higginson DS, Johnson K, Lobato-Busto R, Mollà M, Müller A, Payne D, Peleteiro P, Post G, Rancati T, Rattay T, Reyes V, Rosenstein BS, De Ruysscher D, De Santis MC, Schäfer J, Schnabel T, Sperk E, Symonds RP, Stobart H, Taboada-Valladares B, Talbot CJ, Valdagni R, Vega A, Veldeman L, Ward T, Weißenberger C, West CML, Chang-Claude $\mathrm{J}$ and REQUITE consortium.: REQUITE: A prospective multicentre cohort study of patients undergoing radiotherapy for breast, lung or prostate cancer. Radiother Oncol 138: 59-67, 2019. PMID: 31146072. DOI: 10.1016/j.radonc.2019.04.034

71 Massi MC, Gasperoni F, Ieva F, Paganoni AM, Zunino P, Manzoni A, Franco NR, Veldeman L, Ost P, Fonteyne V, Talbot CJ, Rattay T, Webb A, Symonds PR, Johnson K, Lambrecht M, Haustermans K, De Meerleer G, de Ruysscher D, Vanneste B, Van Limbergen E, Choudhury A, Elliott RM, Sperk E, Herskind C, Veldwijk MR, Avuzzi B, Giandini T, Valdagni R, Cicchetti A, Azria D, Jacquet MF, Rosenstein BS, Stock RG, Collado K, Vega A, Aguado-Barrera ME, Calvo P, Dunning AM, Fachal L, Kerns SL, Payne D, Chang-Claude J, Seibold P, West CML and Rancati T: A deep learning approach validates genetic risk factors for late toxicity after prostate cancer radiotherapy in a REQUITE multi-national cohort. Front Oncol 10: 541281, 2020. PMID: 33178576. DOI: 10.3389/fonc.2020.541281

72 Eade T, Choudhury A, Pollack A, Abramowitz M, Chinea FM, Guo L, Kennedy J, Louw S, Hruby G, Kneebone A and West C: Acute epithelial toxicity is prognostic for improved prostate cancer response to radiation therapy: A retrospective, multicenter, cohort study. Int J Radiat Oncol Biol Phys 101(4): 957-963, 2018. PMID: 29976508. DOI: 10.1016/j.ijrobp.2018.04.009

73 Campostrini F, Musola R, Marchiaro G, Lonardi F and Verlato G: Role of early proctoscopy in predicting late symptomatic proctitis after external radiation therapy for prostate carcinoma. Int J Radiat Oncol Biol Phys 85(4): 1031-1037, 2013. PMID: 22975612. DOI: 10.1016/j.ijrobp.2012.07.2373 
74 Goldner G, Pötter R, Kranz A, Bluhm A and Dörr W: Healing of late endoscopic changes in the rectum between 12 and 65 months after external beam radiotherapy. Strahlenther Onkol 187(3): 202-205, 2011. PMID: 21347635. DOI: 10.1007/s00066-010-2211-5

75 Grodsky MB and Sidani SM: Radiation proctopathy. Clin Colon Rectal Surg 28(2): 103-11, 2015. PMID: 26034407. DOI: 10.1055/s-0035-1547337

76 Takemoto S, Shibamoto Y, Ayakawa S, Nagai A, Hayashi A, Ogino H, Baba F, Yanagi T, Sugie C, Kataoka H and Mimura $\mathrm{M}$ : Treatment and prognosis of patients with late rectal bleeding after intensity-modulated radiation therapy for prostate cancer. Radiat Oncol 7: 87, 2012. PMID: 22691293. DOI: 10.1186/ 1748-717X-7-87

77 Doi H, Kamikonya N, Takada Y, Niwa Y, Fujiwara M, Tsuboi $\mathrm{K}$, Miura H, Inoue H, Tanooka M, Nakamura T, Shikata T, Kimura T, Tsujimura T and Hirota S: Low-dose aspirin therapy does not increase the severity of acute radiation proctitis. World J Oncol 3(4): 173-181, 2012. PMID: 29147301. DOI: 10.4021/ wjon $559 \mathrm{w}$

78 Koukourakis MI, Kyrgias G, Papadopoulou A, Panteliadou M, Giatromanolaki A, Sivridis E, Mavropoulou S, Kalogeris K, Nassos P, Milioudis N and Touloupidis S: Treatment of lowrisk prostate cancer with radical hypofractionated accelerated radiotherapy with cytoprotection (HypoARC): an interim analysis of toxicity and efficacy. Anticancer Res 31(5): 17451751, 2011. PMID: 21617234.

79 Stefanelli A, Pascale G, Rainieri E, Ursino S, Colella M, Zini G, Berretta $M$ and Fiorica F: Can we decrease the acute proctitis in prostate cancer patients using hyaluronic acid during radiation therapy: a prospective historically controlled clinical study. Eur Rev Med Pharmacol Sci 16(5): 639-645, 2012. PMID: 22774405.

80 McElvanna K, Wilson A and Irwin T: Sucralfate paste enema: a new method of topical treatment for haemorrhagic radiation proctitis. Colorectal Dis 16(4): 281-284, 2014. PMID: 24299100. DOI: 10.1111/codi.12507

81 Chruscielewska-Kiliszek MR, Regula J, Polkowski M, Rupinski M, Kraszewska E, Pachlewski J, Czaczkowska-Kurek E and Butruk E: Sucralfate or placebo following argon plasma coagulation for chronic radiation proctitis: a randomized double blind trial. Colorectal Dis 15(1): e48-55, 2013. PMID: 23006660. DOI: $10.1111 /$ codi.12035

82 Maggio A, Magli A, Rancati T, Fiorino C, Valvo F, Fellin G, Ricardi U, Munoz F, Cosentino D, Cazzaniga LF, Valdagni R and Vavassori V: Daily sodium butyrate enema for the prevention of radiation proctitis in prostate cancer patients undergoing radical radiation therapy: results of a multicenter randomized placebo-controlled dose-finding phase 2 study. Int J Radiat Oncol Biol Phys 89(3): 518-524, 2014. PMID: 24803033. DOI: 10.1016/j.ijrobp.2014.03.018

83 Alashkham A, Paterson C, Rauchhaus P and Nabi G: Can Angiotensin-converting enzyme inhibitors reduce the incidence, severity, and duration of radiation proctitis? Int J Radiat Oncol Biol Phys 94(1): 93-101, 2016. PMID: 26547382. DOI: 10.1016/j.ijrobp.2015.09.013

84 Jensen MM, Jia W, Isaacson KJ, Schults A, Cappello J, Prestwich GD, Oottamasathien S and Ghandehari H: Silkelastinlike protein polymers enhance the efficacy of a therapeutic glycosaminoglycan for prophylactic treatment of radiation-induced proctitis. J Control Release 263: 46-56, 2017. PMID: 28232224. DOI: 10.1016/j.jconrel.2017.02.025

85 Qin SB, Gao XS, Li HZ, Liu CX, Hou DL, Nian WD, Li XY and Wang D: Intra-rectal use of epinephrine in radiotherapy of prostate cancer. Cancer Manag Res 11: 4847-4854, 2019. PMID: 31213905. DOI: 10.2147/CMAR.S187049

86 Sahebnasagh A, Ghasemi A, Akbari J, Alipour A, Lashkardoost H, Ala S, Hosseinimehr SJ and Salehifar E: Prevention of acute radiation-induced Proctitis by Aloe vera: a prospective randomized, double-blind, placebo controlled clinical trial in Pelvic Cancer patients. BMC Complement Med Ther 20(1): 146, 2020. PMID: 32404169. DOI: 10.1186/s12906-020-02935-2

87 Saadipoor A, Razzaghdoust A, Simforoosh N, Mahdavi A, Bakhshandeh M, Moghadam M, Abdollahi H and Mofid B: Randomized, double-blind, placebo-controlled phase II trial of nanocurcumin in prostate cancer patients undergoing radiotherapy. Phytother Res 33(2): 370-378, 2019. PMID: 30427093. DOI: $10.1002 /$ ptr.6230

88 Nascimento M, Caporossi C, Eduardo Aguilar-Nascimento J, Michelon Castro-Barcellos H, Teixeira Motta R and Reis Lima $\mathrm{S}$ : Efficacy of synbiotics to reduce symptoms and rectal inflammatory response in acute radiation proctitis: A randomized, double-blind, placebo-controlled pilot trial. Nutr Cancer 72(4): 602-609, 2020. PMID: 31364875. DOI: 10.1080/01635581.2019.1647254

89 Swan MP, Moore GT, Sievert W and Devonshire DA: Efficacy and safety of single-session argon plasma coagulation in the management of chronic radiation proctitis. Gastrointest Endosc 72(1): 150-154, 2010. PMID: 20493484. DOI: 10.1016/j.gie. 2010.01 .065

90 Hortelano E, Gómez-Iturriaga A, Ortiz-de-Zárate R, Zaballa M, Barturen Á, Casquero F, San-Miguel Í, Carvajal C, Cacicedo J, Del-Hoyo O, Lupiani J, Pérez F and Bilbao P: Is argon plasma coagulation an effective and safe treatment option for patients with chronic radiation proctitis after high doses of radiotherapy? Rev Esp Enferm Dig 106(3): 165-170, 2014. PMID: 25007015.

91 Weiner J, Schwartz D, Martinez M, Safdieh J, Aytaman A and Schreiber D: Long-term results on the efficacy of argon plasma coagulation for patients with chronic radiation proctitis after conventionally fractionated, dose-escalated radiation therapy for prostate cancer. Pract Radiat Oncol 7(1): e35-e42, 2017. PMID: 27663931. DOI: $10.1016 /$ j.prro.2016.07.009

92 Yeoh E, Tam W, Schoeman M, Moore J, Thomas M, Botten R and Di Matteo A: Argon plasma coagulation therapy versus topical formalin for intractable rectal bleeding and anorectal dysfunction after radiation therapy for prostate carcinoma. Int J Radiat Oncol Biol Phys 87(5): 954-959, 2013. PMID: 24113059. DOI: 10.1016/j.ijrobp.2013.08.034

93 Dziki Ł, Kujawski R, Mik M, Berut M, Dziki A and Trzciński R: Formalin therapy for hemorrhagic radiation proctitis. Pharmacol Rep 67(5): 896-900, 2015. PMID: 26398382. DOI: 10.1016/j.pharep.2015.03.006

94 Viani GA and Sakamoto A: Outpatient application of formalin for chronic rectal bleeding after prostate irradiation: a quasiexperimental study. Int J Colorectal Dis 32(7): 1037-1040, 2017. PMID: 28108788. DOI: 10.1007/s00384-017-2759-y

95 Clavo B, Ceballos D, Gutierrez D, Rovira G, Suarez G, Lopez L, Pinar B, Cabezon A, Morales V, Oliva E, Fiuza D and Santana-Rodriguez N: Long-term control of refractory 
hemorrhagic radiation proctitis with ozone therapy. J Pain Symptom Manage 46(1): 106-112, 2013. PMID: 23102757. DOI: $10.1016 /$ j.jpainsymman.2012.06.017

96 Oscarsson N, Arnell P, Lodding P, Ricksten SE and SeemanLodding $\mathrm{H}$ : Hyperbaric oxygen treatment in radiation-induced cystitis and proctitis: a prospective cohort study on patientperceived quality of recovery. Int J Radiat Oncol Biol Phys 87(4): 670-675, 2013. PMID: 24035333. DOI: 10.1016/j.ijrobp. 2013.07.039

97 Andren J and Bennett MH: An observational trial to establish the effect of hyperbaric oxygen treatment on pelvic late radiation tissue injury due to radiotherapy. Diving Hyperb Med 50(3): 250-255, 2020. PMID: 32957127. DOI: 10.28920/ dhm50.3.250-255

98 Rustagi T, Corbett FS and Mashimo H: Treatment of chronic radiation proctopathy with radiofrequency ablation (with video). Gastrointest Endosc 81(2): 428-436, 2015. PMID: 24973172. DOI: $10.1016 /$ j.gie.2014.04.038

99 De Robles MS and Young CJ: Rubber band ligation of hemorrhoids is often a necessary complement in the management of hemorrhagic radiation proctitis. Scand J Surg 109(2): 108-114, 2020. PMID: 30632450. DOI: $10.1177 / 1457496918822619$

100 Huang X, Zhong Q, Wang H, Zhao J, Kuang Y, Guan Q, He Y, Qin Q, Wang H and Ma T: Diverting colostomy is an effective procedure for ulcerative chronic radiation proctitis patients after pelvic malignancy radiation. BMC Surgery 20(1), 2020. DOI: 10.1186/s12893-020-00925-2
101 Pui WC, Chieng TH, Siow SL, Nik Abdullah NA and Sagap I: A randomized controlled trial of novel treatment for hemorrhagic radiation proctitis. Asian Pac J Cancer Prev 21(10): 2927-2934, 2020. PMID: 33112550. DOI: 10.31557/APJCP.2020.21.10.2927

102 White K and Henson C: Endoscopically delivered Purastat for the treatment of severe haemorrhagic radiation proctopathy: a service evaluation of a new endoscopic treatment for a challenging condition. Frontline Gastroenterology: flgastro2020-101735, 2021. DOI: 10.1136/flgastro-2020-101735

103 Weiner JP, Wong AT, Schwartz D, Martinez M, Aytaman A and Schreiber D: Endoscopic and non-endoscopic approaches for the management of radiation-induced rectal bleeding. World J Gastroenterol 22(31): 6972-6986, 2016. PMID: 27610010. DOI: $10.3748 /$ wjg.v22.i31.6972

104 Murofushi KN, Yoshioka Y, Ishikawa H, Sumi M, Okumura T, Oguchi $M$ and Sakurai H: Selection criteria and clinical outcomes of patients with asymmetrical cervical cancer treated with various high-dose-rate brachytherapy techniques. Anticancer Res 40(2): 999-1006, 2020. PMID: 32014945. DOI: 10.21873/anticanres.14034

Received January 12, 2021

Revised February 7, 2021

Accepted February 12, 2021 